\title{
Study on Technological Process Innovation of Non-Cyanide Leaching
}

\author{
$\mathrm{Xu} \mathrm{Chao}^{1}$, Cai Mingming ${ }^{1}$, Gao Tengyue $^{1}$, Li guangsheng $^{1}$, Zhu xingfu ${ }^{1}$, Lu Zhongbo ${ }^{1}$, Chen Yanbo ${ }^{1}, Z^{2}$ hang juntong ${ }^{1}$, Qin \\ Guanglin $^{1}$, Ji Qiang ${ }^{1}$, Yu Congquan ${ }^{1}$ \\ ${ }^{1}$ Metallurgical Laboratory Branch of Shandong Gold Mining Technology Co., Ltd.Laizhou City, Shandong Province, China 261400
}

\begin{abstract}
Nowadays, there are many gold leaching processes, and the dominant one is cyanidation, but the virulence of cyanidation seriously endangers the environment and human health. In order to reduce environmental pollution and improve the recovery rate of gold, metallurgical workers put forward a variety of new gold leaching methods, which can be roughly divided into two types: one is to develop pretreatment technology on the basis of traditional cyanidation method; The other is non-cyanide leaching of gold. Based on the existing Non-Cyanide leaching technology, this paper puts forward the process innovation of NonCyanide leaching technology, thiourea method and dilute nitric acid pre-oxidation treatment process. The thiourea non-cyanide leaching system was investigated. According to the leaching situation of gold and silver in raw ore, the innovative scheme of gold and silver leaching technology was selected. Compared with other treatment methods, thiourea method and dilute nitric acid pre-oxidation treatment technology overcome the danger of high pressure, and the nitrogen oxide gas produced in the dilute nitric acid oxidation process can be recycled, which basically does not pollute the environment.
\end{abstract}

\section{Introduction}

With the development of science and technology, the use of gold is becoming more and more extensive, and the consumption of gold is also increasing. The gold ore with low grade, fine disseminated, high impurity content and difficult to process has become the main raw material for gold production in China. The reasons why this kind of gold deposits are difficult to beneficiate and smelt are mainly shown in [1-4]: Fine-grained gold or submicroscopic gold exists in sulfide ores in the form of wrapping or impregnation, and the main gold-bearing sulfides are pyrite and arsenopyrite. There are many sulfides of base metals in gold ore, and their decomposition products will interfere with cyanide leaching of gold.

Since the late 19th century, cyanide has been gradually applied to the industrial production of gold ore leaching. Because of its simple operation, low consumption of reagents and low production cost, cyanide has been widely used in major mining companies and is still in use today. However, cyanide also has many shortcomings in the process of gold leaching, such as: the leaching rate of gold minerals coated with fine particles is low; Base metals in gold-bearing ores will consume cyanide; It is difficult to separate high-grade tailings from cyanide leaching. Cyanide, as a hazardous chemical, requires strict conditions during use and transportation [5]. The virulence of cyanide seriously affects the working environment. Therefore, how to realize green extraction of gold from minerals has become the focus of many scholars. On the basis of previous studies, this paper classifies, summarizes and comments the current gold leaching reagents and technological methods, and studies and conceives a new and more effective non-cyanide gold leaching method.

\section{Application status of Non-Cyanide leaching}

\subsection{Pressure oxidation leaching of gold}

With the continuous exploitation of gold mines, the quantity of high-grade and easy-to-handle raw ore is decreasing year by year. According to statistics, about $2 / 3$ of the existing gold reserves in the world are difficult to treat, especially high-sulfur minerals such as arsenopyrite and pyrite. Gold is generally coated by these sulfides in the form of fine-grained disseminated. Traditional grinding treatment can not achieve the monomer dissociation or exposed surface of gold and gold-bearing minerals, which leads to insufficient contact between gold leaching solvent and gold, and ultimately affects the leaching rate of gold [6].

Pressurized oxidation pretreatment is a process which is studied more at present. It is mainly aimed at refractory gold-bearing minerals with high arsenic and high sulfur. This method can completely destroy sulfide package, and has less environmental pollution, fast reaction rate and high leaching rate.

In reference [7], an experimental study on pressure 
oxidation-chlorination leaching of a flotation high-sulfur and high-arsenic gold concentrate was carried out. The experimental results show that at $180^{\circ} \mathrm{C}$, the oxygen partial pressure is $0.8 \mathrm{M} \mathrm{Pa}$, and the particle size of treated gold concentrate is- $0.075 \sim+0.061 \mathrm{~mm}$; The ratio of liquid to solid was $4: 1$, the initial acidity was controlled at $60 \mathrm{~g} / 1$, the revolution of $600 \mathrm{r} / \mathrm{m}$ in, and the desulfurization rate of gold concentrate reached $98.35 \%$ after reaction for $2 \mathrm{~h}$. Then, the leaching experiment was carried out with the mixed solution of sodium chloride and sodium hypochlorite as leaching agent. Under the best conditions, the leaching rate of gold reached $94.54 \%$, which was $42.65 \%$ higher than that of the oxidation sample without pressure

\subsection{Bromination and iodination}

The research on extracting gold from primary ore of purple wood letter by soaking in bromine-sodium bromide solution shows that the leaching rate of gold reaches $90 \%$ after soaking for $15 \sim 20$ days, and bromine can be regenerated by chlorine gas. The gold recovery rate is over $97 \%$ after leaching sulfur-bearing gold ore calcine with sodium chloride-bromine water method. Literature [8] uses bromide as catalyst to accelerate the gold leaching rate of sodium hypochlorite and sodium chloride system, and obtains satisfactory results.

Bromination is a new process which is beneficial to environmental protection. It is characterized by short leaching time, high recovery rate of gold, similar reagent cost to cyanide method, low pollution and recyclable bromine, which is consistent with the advocated green metallurgy direction.

There are few research reports on iodine leaching technology in China, which is mainly used in the recovery of industrial waste gold. Literature [9] demonstrates that $\mathrm{AuI}_{2}^{-}$complex is more stable than $\mathrm{AuCI}_{2}^{-}$complex, and iodide is an excellent complexing agent for gold leaching. The research in reference [10] shows that $\mathrm{I}_{3}^{-}$is the main oxidant in $\mathrm{Au}-\mathrm{I}^{-}-\mathrm{I}_{2}-\mathrm{H}_{2} \mathrm{O}$ and $\mathrm{Au}-\mathrm{I}^{-}-\mathrm{ClO}^{-}-\mathrm{H}_{2} \mathrm{O}$ systems, and points out that $\mathrm{I}_{2}(\mathrm{~s})$ will be generated when $\mathrm{ClO}^{-}$and $\mathrm{I}^{-}$meet.

Iodization gold leaching process is generally carried out in weak alkaline medium, which is easy to solve the problem of equipment corrosion protection, and it is a promising gold leaching method with less reagent consumption and less pollution.

\subsection{Stone sulfur mixture method}

Stone sulfur mixture method was first proposed by domestic scholars, which is a polysulfide gold leaching reagent synthesized by lime and sulfur. It is easy to synthesize, non-toxic, rapid in gold leaching, strong in adaptability to refractory gold ores, high in gold leaching rate, alkaline in medium and low in requirements for equipment and materials. Its main components are calcium polysulfide and thiosulfate.

The mechanism of leaching gold with stone sulfur mixture is generally electrochemical-catalytic mechanism. In the sulfuric acid mixture solution containing copper and ammonia, $\mathrm{NH}_{4}{ }^{+}$catalyzed the complex reaction of polysulfide ions and thiosulfate ions with gold ions at the anode, while $\mathrm{Cu}\left(\mathrm{NH}_{4}\right)^{2+}$ catalyzed the reduction reaction of oxygen at the cathode. In the aspect of research and popularization, the Research Center of Heap Leaching Technology for Low-grade Gold Mines of Shaanxi Bureau of Geology and Mineral Exploration and Development and South Africa have conducted industrial experimental research [11].

\subsection{Thiosulfate method}

Thiosulfate method has the advantages of rapid gold leaching, insensitivity to impurities such as arsenic and antimony, innocuity, environmental protection and easy degradation. The United States has studied the technical possibility of extracting gold and silver from heavy metal ores containing copper, antimony, arsenic, scandium, tellurium and manganese by thiosulfate method, and built a thiosulfate gold extraction plant in Mexico, but its operation is not normal enough. Literature [12] has carried out an industrial test of gold extraction with thiosulfate.

Thiosulfate leaching process conditions are harsh. It is necessary to keep a certain amount of free ammonia in the solution system with $\mathrm{pH}$ value $>9.2$ and make copper in the solution become complex ions of copper and ammonia, so as to keep the stable existence of thiosulfate in the solution. In addition, this process has some problems such as high reagent concentration, high drug consumption and environmental protection treatment of ammonia nitrogen wastewater.

\subsection{Thiourea method}

Thiourea has strong complexing ability, and can quickly form complex $\mathrm{Au}\left(\mathrm{H}_{2} \mathrm{NCSNH}_{2}\right)_{2}^{2+}$ with gold under strong acid condition, and its stability is very high. In the presence of acidic medium and oxidant, thiourea can greatly reduce the electrode potential of $\mathrm{Au}^{+} / \mathrm{Au}$ pair and form a stable complex with gold.

The technological shortcomings of thiourea method are also obvious [13]: thiourea is easy to decompose, and the reagent consumption in the leaching process is large; It is expensive and the economic benefit is not as good as cyanide method. Thiourea method is not suitable for treating ores containing more alkaline gangue. The process of recovering gold from precious liquid is not as mature and simple as zinc powder replacement process. Immersing gold in acidic medium is easy to corrode equipment; Thiourea may cause cancer and so on. 


\section{Exploration and test of new technical process of Non-Cyanide leaching}

\subsection{Thiourea method}

Since most of gold and silver are evenly distributed in hematite-limonite, magnetic separation, gravity separation and flotation can not enrich gold and silver well. Finally, it is decided to adopt leaching method. Under the guidance of the development trend of green mines, non-cyanide leaching technology is adopted in the experiment. At present, the typical non-cyanide leaching methods in industry include thiourea method, thiosulfate method, iodination method, halogen method and so on.

After grinding the raw ore to a fineness of $-0.084 \mathrm{~mm}$ and a content of $90.50 \%$, the raw ore was dried, scattered and fully mixed as the leaching sample. The mixed sample was sampled by Jiugongge method and screened. The maximum particle size of the sample under the grinding fineness was $0.4 \mathrm{~mm}$, and the empirical formula calculated that the Ms was $55 \mathrm{~g}$. Therefore, the test decided to take $150 \mathrm{~g}$ for leaching test every time. After the leaching test, the leaching residue is filtered by vacuum filter, in which distilled water washes the leaching residue several times during the filtering process, and finally the gold and silver grades in the leaching residue are tested to deduce the leaching rate of precious metals.

\subsubsection{Acid thiourea leaching}

Thiourea has strong complexing ability in acidic environment and in the presence of oxidant. Thiourea has little toxicity and is not easily interfered by copper, arsenic and iron. It has certain advantages in leaching precious metal gold and silver from limonite type gold and silver ore. Adjust the pulp concentration to $23 \%$, adjust the $\mathrm{pH}$ value of pulp to $1.5 \sim 2.5$ with $6 \%$ dilute sulfuric acid, and add $60 \mathrm{~kg} / \mathrm{t}$ thiourea to directly stir and leach for $3.5 \mathrm{~h}$ hours. See fig. 1 for test flow and table 1 for test results.

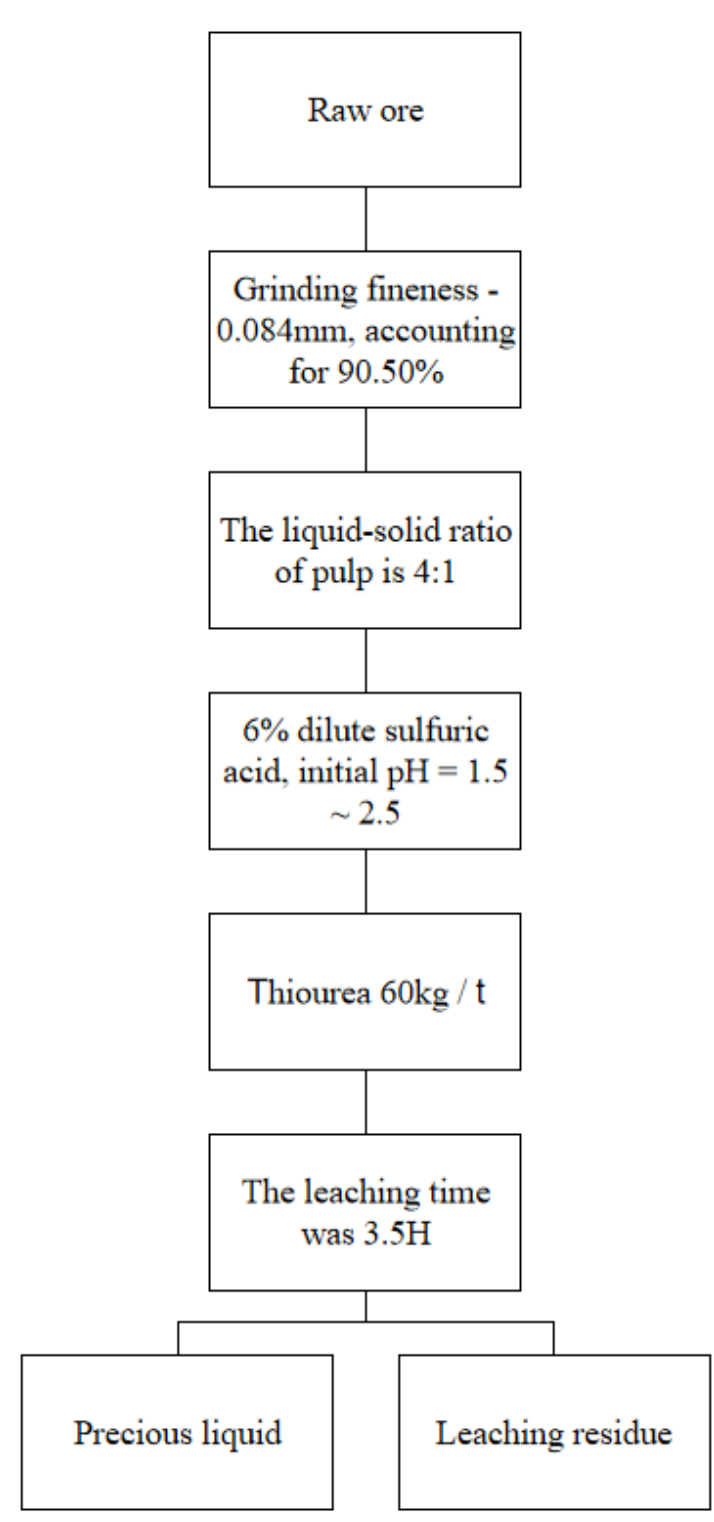

Figure 1 Acid thiourea leaching test flow

Table 1 Experimental results of acid thiourea leaching

\begin{tabular}{cccccc}
\hline & & \multicolumn{2}{c}{ Grade } & \multicolumn{2}{c}{ Recovery rate $\%$} \\
Product & $\begin{array}{c}\text { Productive } \\
\text { rate } / \%\end{array}$ & $\mathrm{Au} / \mathrm{g} / \mathrm{t}$ & $\mathrm{Au} / \mathrm{g} / \mathrm{t}$ & $\mathrm{Au}$ & $\mathrm{Ag}$ \\
\cline { 3 - 6 } & & - & - & 44.18 & 29.87 \\
\hline $\begin{array}{c}\text { Precious } \\
\text { liquid }\end{array}$ & - & 0.88 & 72.24 & 56.93 & 70.12 \\
\hline $\begin{array}{c}\text { Leaching } \\
\text { slag }\end{array}$ & 96.33 & 1.25 & 106.29 & 100.00 & 100.00 \\
\hline Raw ore & 100.00 & & & & \\
\hline
\end{tabular}

According to the test results in Table 1, the leaching rate of gold and silver is only $44.18 \%$ and $29.87 \%$, respectively, while the consumption of thiourea is as high as $50 \mathrm{~kg} / \mathrm{t}$, which is unsatisfactory. The analysis reason is that the content of hematite and limonite and carbonate minerals in the raw ore is high, and these minerals are easy to react with acid at low $\mathrm{pH}$ value, thus changing the acidbase environment of leaching. In addition, the gold and silver are distributed with very fine grain size, which is wrapped by iron oxide minerals, and thiourea cannot reach the surface of gold and silver. 


\subsubsection{Alkaline thiourea leaching}

In view of the $\mathrm{pH}$ value of thiourea leaching environment, there is a consensus in most studies that thiourea is very unstable in alkaline solution and easily decomposed into sulfide and cyanamide. However, some studies have found that the combination of sodium silicate and oxidant potassium ferricyanide can be used as a stabilizer of thiourea in alkaline environment, which can inhibit the irreversible decomposition of thiourea under alkaline conditions to a certain extent, so as to realize the leaching of gold and silver by alkaline thiourea solution. See fig. 2 for the test flow of alkaline thiourea leaching and table 2 for the test results.

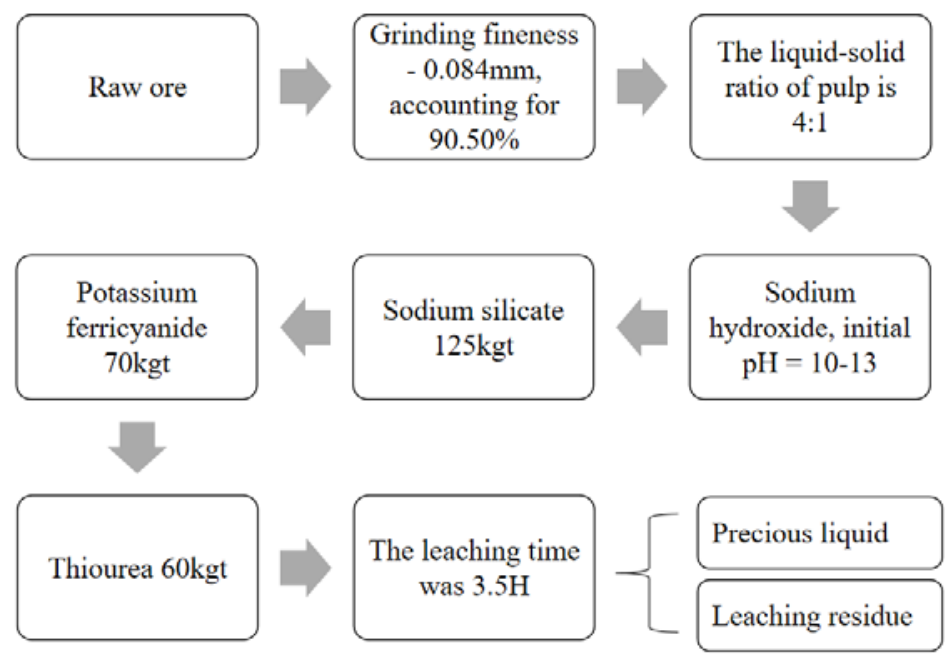

Figure 2 Test flow of alkaline thiourea leaching

Table 2 Experimental results of alkaline thiourea leaching

\begin{tabular}{cccccc}
\hline & & \multicolumn{2}{c}{ Grade } & \multicolumn{2}{c}{ Recovery rate $\%$} \\
\cline { 3 - 6 } Product & $\begin{array}{c}\text { Productive } \\
\text { rate } / \%\end{array}$ & $\mathrm{Au} / \mathrm{g} / \mathrm{t}$ & $\mathrm{Au} / \mathrm{g} / \mathrm{t}$ & $\mathrm{Au}$ & $\mathrm{Ag}$ \\
& & - & - & 19.07 & 14.75 \\
\hline $\begin{array}{c}\text { Precious } \\
\text { liquid }\end{array}$ & 97.33 & 1.37 & 88.92 & 80.26 & 87.39 \\
\hline $\begin{array}{c}\text { Leaching } \\
\text { slag }\end{array}$ & 100.00 & 1.66 & 1.02 .28 & 100.00 & 100.00 \\
\hline Raw ore & & & & & \\
\hline
\end{tabular}

It can be seen from Table 2 that the leaching rate of gold and silver obtained by alkaline thiourea gold leaching system is only $19.07 \%$ and $14.75 \%$, which indicates that alkaline conditions will worsen thiourea gold leaching system, and the combination of sodium silicate and sodium ferricyanide cannot prevent the decomposition of thiourea.

\subsection{Dilute nitric acid pre-oxidation treatment process}

To extract gold from gold concentrate, it is generally necessary to oxidize sulfide in gold concentrate and dissociate the wrapped gold before leaching gold. The main pre-oxidation methods are fire method and wet method, and the wet method is divided into chemical oxidation and bacterial oxidation. The nitric acid oxidation method in chemical oxidation is studied here.

In the process of oxidizing sulfide ore with dilute nitric acid at normal pressure. The new ecological sulfur will form a secondary package, resulting in the secondary leaching of gold. Therefore, how to overcome the secondary wrapping of gold will be a problem to be solved in the process. Two methods are proposed for the test: (1) the oxidized slag is desulfurized by alkali; (2) In the process of nitric acid oxidation, ultrasonic waves are used to separate sulfur from the surface of gold, and the surface of gold can be cleaned to keep high activity of gold; By desulfurizing the oxidation slag or dispersing sulfur in the oxidation process, the adverse effects of elemental sulfur on the subsequent cyanidation and gold extraction can be thoroughly solved. Chlorinated ore pulp electrolysis and Non-Cyanide gold leaching are carried out on the oxidized slag after desulfurization or sulfur dispersion.

The solid-liquid ratio is controlled to be 1: 6 , considering that it is difficult to achieve closed circulation under test conditions. During the reaction, a small amount of nitric acid will volatilize in the form of nitrogen oxides and be recovered in the subsequent dilute nitric acid washing cylinders. In order to complete the reaction, the added nitric acid should be excessive.

The reacted slag is treated by two methods: (1) direct chlorination and electrolysis; (2) Chlorination electrolysis after desulfurization. The first test was $250 \mathrm{~g}$, the weight after oxidation was $66 \mathrm{~g}$, and the desulfurization was done by alkali cooking. The slag was added to $6 \% \mathrm{NaOH}$ solution and boiled to dissolve sulfur. The weight of ore was reduced by $5 \mathrm{~g}$, and the final weight of slag was $61 \mathrm{~g}$. The oxidized slag was desulfurized and electrolyzed. In the second test, the ore weight is $300 \mathrm{~g}$, and the oxidized ore weight is $90 \mathrm{~g}$, and $50 \mathrm{~g}$ is taken for direct electrolysis. In the third test, the ore weight was $280 \mathrm{~g}$, and the dilute nitric acid oxidation was enhanced by ultrasonic wave, and the oxidized slag was directly electrolyzed. X-ray analysis of slag shows that the oxidation condition is ideal, and the main components in slag are $\mathrm{S}$ and $\mathrm{SiO}_{2}$. See Table 33 for test methods and their effects. 
Table 3 Experimental factors of leaching gold from chlorinated slag of gold concentrate

\begin{tabular}{cccc}
\hline Project & $\begin{array}{c}\text { Ore sample } \\
\text { of test } 1\end{array}$ & $\begin{array}{c}\text { Ore sample of } \\
\text { test } 2\end{array}$ & $\begin{array}{c}\text { Ore sample of } \\
\text { test 3 }\end{array}$ \\
\cline { 2 - 4 } $\begin{array}{c}\text { Ultrasonic } \\
\text { wave is not } \\
\text { added when } \\
\text { nitric acid is } \\
\text { oxidized }\end{array}$ & $\begin{array}{c}\text { Ultrasonic } \\
\text { wave is not } \\
\text { added during } \\
\text { dilute nitric } \\
\text { acid oxidation }\end{array}$ & $\begin{array}{c}\text { Ultrasonic } \\
\text { wave in dilute } \\
\text { nitric acid } \\
\text { oxidation }\end{array}$ \\
\hline $\begin{array}{c}\text { Ore sample } \\
\text { weight } / \mathrm{g}\end{array}$ & 61 & 50 & 50 \\
\hline $\begin{array}{c}\text { Desulfurization } \\
\text { method }\end{array}$ & $\begin{array}{c}\text { Elution with } \\
6 \% \text { NaOH } \\
\text { solution }\end{array}$ & $\begin{array}{c}\text { Electrolytic } \\
\text { desulfurization }\end{array}$ & $\begin{array}{c}\text { Electrolytic } \\
\text { desulfurization }\end{array}$ \\
\hline $\begin{array}{c}\text { Gold leaching } \\
\text { method }\end{array}$ & $\begin{array}{c}\text { Chlorination } \\
\text { electrolysis }\end{array}$ & $\begin{array}{c}\text { Chlorination } \\
\text { electrolysis }\end{array}$ & $\begin{array}{c}\text { Chlorination } \\
\text { electrolysis }\end{array}$ \\
\hline $\begin{array}{c}\text { Grade before } \\
\text { gold leaching/ } \\
\left(\mathrm{g} \cdot \mathrm{t}^{-1}\right)\end{array}$ & 187.36 & 189.01 & 177.24 \\
\hline $\begin{array}{c}\text { Grade after } \\
\text { immersion in } \\
\text { gold/ }\end{array}$ & 24.57 & 106.87 & 99.21 \\
$\left(\mathrm{~g} \cdot \mathrm{t}^{-1}\right)$ & 86.28 & 44.27 & 51.06 \\
\hline $\begin{array}{c}\text { Gold leaching } \\
\text { rate } \%\end{array}$ & & & \\
\hline
\end{tabular}

The following conclusions can be drawn from table 3 and the above tests:

(1). After desulfurization with $6 \% \mathrm{NaOH}$ lye, the chlorination leaching effect is better, and the leaching rate reaches $86.28 \%$. The effect of dispersing elemental sulfur in dilute nitric acid oxidation at atmospheric pressure by ultrasonic wave is obvious. It shows that it is difficult to treat ores with high sulfur content by chlorination electrolytic gold leaching, while it is feasible for ores with low sulfur content.

(2). In view of $10 \%$ of gold in concentrate, it is difficult to oxidize by nitric acid. the treatment of sulfide wrapped gold by this method has reached a high level, and most of the gold contained in slag may be wrapped by silicate.

(3). From the test results, the existence of carbon did not significantly affect the gold leaching effect after nitric acid pretreatment. This shows that this method may passivate the carbon of this mine.

(4). Compared with other treatment methods, this method overcomes the danger of high pressure, and its working environment is carried out under normal pressure and temperature lower than 85 $93{ }^{\circ} \mathrm{C}$, so the requirements for equipment are greatly reduced; The nitrogen oxide gas produced in the dilute nitric acid oxidation process can be recycled, and basically does not pollute the environment.

\section{Summary}

With the large-scale development of gold mines around the world, refractory gold mines have gradually become the main resources of gold industry in the future, and the emergence of corresponding new processes, technologies and equipment will greatly improve the utilization efficiency of refractory gold mines. Roasting oxidation, hot-pressing oxidation and microbial oxidation, as three pretreatment processes popularized and applied by gold production enterprises in the world, are interdependent and expanding in the application field of refractory gold mines due to their unique technical characteristics and adaptability. The leaching of gold and silver from raw ore by thiourea was compared. It was found that the content of limonite and carbonate minerals in raw ore was high, and these minerals easily reacted with acid at low $\mathrm{pH}$ value, thus changing the acid-base environment of leaching. Compared with other treatment methods, the dilute nitric acid pre-oxidation treatment technology overcomes the danger of high pressure. The nitrogen oxide gas produced in the dilute nitric acid oxidation process can be recycled and basically does not pollute the environment.

\section{References}

1. Altinkaya P, Wang Z, Korolev I, et al. Leaching and recovery of gold from ore in Non-Cyanide glycine media[J]. Minerals Engineering, 2020, 158:106610.

2. Ahtiainen R, M Lundström. Non-Cyanide gold leaching in exceptionally mild chloride solutions[J]. Journal of Cleaner Production, 2019, 234:9-17.

3. Zhang $\mathrm{C}$, Wang $\mathrm{X}$, Jiang $\mathrm{S}$, et al. Heavy metal pollution caused by cyanide gold leaching: a case study of gold tailings in central China[J]. Environmental Science and Pollution Research, 2021:1-10.

4. Elomaa H, Sinisalo P, Rintala L, et al. Process simulation and gate-to-gate life cycle assessment of hydrometallurgical refractory gold concentrate processing[J]. The International Journal of Life Cycle Assessment, 2020, 25(3):456-477.

5. Altnkaya P, Liipo J, Kolehmainen E, et al. Leaching of Trace Amounts of Metals from Flotation Tailings in Cupric Chloride Solutions[J]. Mining, Metallurgy \& Exploration, 2019, 36(2):335-342.

6. Karimova L M, Zakharyan D V, Agapitov Y E. Research on Hydrometallurgical Processing of GoldConcentrate of Jamgyr Deposit[J]. Journal of Siberian Federal University Engineering \& Technologies, 2021:166-174.

7. Kim R, Ghahreman A. The effect of ore mineralogy on the electrochemical gold dissolution behavior in various cyanide and oxygen concentrations; Effect of sulfidic ores containing heavy metals[J]. Hydrometallurgy, 2019, 184:75-87.

8. Hou D, Liu L, Yang Q, et al. Decomposition of Cyanide from Gold Leaching Tailingsby Using Sodium Metabisulphite and Hydrogen Peroxide[J]. Advances in Materials Science and Engineering, 2020, 2020(3):1-7.

9. Shafie N S, Zaini N, Ali N F. Gold extraction via cyanide leaching using alkaline-based empty fruit bunch activated carbon[J]. IOP Conference Series Materials Science and Engineering, 2020, 808:012010. 
10. Barani K, Dehghani M, Azadi M R, et al. Leaching of a polymetal gold ore and reducing cyanide consumption using cyanide-glycine solutions[J]. Minerals Engineering, 2021, 163:106802.

11. Li H, Oraby E A, Eksteen J J. Cyanide consumption minimisation and concomitant toxic effluent minimisation during precious metals extraction from waste printed circuit boards[J]. Waste Management, 2021, 125(5):87-97.

12. Salazar R P, He C, Jacome H M, et al. Acidic pretreatment of a copper-silver ore and its beneficial effect on cyanide leaching[J]. Minerals Engineering, $2020,149$.

13. Izabela, Dobrosz-Gómez, Miguel, et al. Mineralization of cyanide originating from gold leaching effluent using electro-oxidation: multiobjective optimization and kinetic study[J]. Journal of Applied Electrochemistry, 2020, 50(2):217-230. 